\title{
ARTISTAS INDÍGENAS: PROCESSOS DE INCLUSÃO NO CENÁRIO ARTÍSTICO RORAIMENSE ${ }^{1}$
}

\section{INDIGENOUS ARTISTS: PROCEDURES FOR INCLUSION IN THE SCENARIO ARTISTIC RORAIMENSE}

\author{
Cristiane Bade FAVRETO* \\ Anderson dos Santos PAIVA**
}

Resumo: O presente artigo versa sobre a promoção da arte e cultura indígenas no Estado de Roraima destacando o papel desempenhado pela Universidade Federal de Roraima (UFRR) com o objetivo de divulgar e conscientizar a população sobre importância da vertente multiétnica na construção da identidade local. Nele apresentamos o cenário atual e problematizamos as principais questões a respeito da construção do espaço para as artes indígenas, bem como os entraves e obstáculos ao pleno desenvolvimento das práticas representações artísticas das diversas etnias em Roraima. Para tanto, rediscutimos alguns conceitos sobre na relação entre a arte e antropologia e o processo de fortalecimento do projeto discursivo desses artistas para dar ênfase a valorização da diversidade cultural do Estado.

Palavras-chave: Artes Indígenas. Patrimônio. Identidade cultural.

\begin{abstract}
This article deals with the promotion of indigenous art and culture in the State of Roraima highlighting the role of the Federal University of Roraima (UFRR) in order to disseminate and raise awareness about the importance of multi-ethnic aspect in the construction of local identity. We present the current situation and confront the main issues regarding the construction of space for indigenous arts as well as barriers and obstacles to the full development of practical artistic representations of the various ethnic groups in Roraima. Therefore, we rediscutimos some concepts about the relationship between art and anthropology and the strengthening process of discursive design of these artists to emphasize the appreciation of cultural diversity of the state.
\end{abstract}

Keywords: Indigenous Arts. Equity. Cultural identity.

\section{Introdução}

Roraima é um dos mais novos estados da federação e possuí características muito particulares devido a sua forte matriz cultural indígena claramente verificável em grande parte de sua extensão territorial em que $46,37 \%$ da área do Estado pertence à reservas indígenas homologadas ${ }^{2}$. Outro elemento de grande destaque na constituição da população roraimense são os migrantes nordestinos ${ }^{3}$, originários principalmente do Estado do Maranhão, e que foram

\footnotetext{
* Mestre em História pelo Programa de Pós-Graduação em História da Universidade Estadual do Oeste do Paraná. Professora do curso de Artes Visuais da Universidade Federal de Roraima (UFRR). E-mail: cristiane.bade@ufrr.br.

** Doutorando pelo Programa de Pós-Graduação em Arte Contemporânea da Universidade de Coimbra. Professor do curso de Artes Visuais da Universidade Federal de Roraima (UFRR). Email: anderson.paiva@ufrr.br.
} 
responsáveis pela disseminação de elementos culturais que passaram a fazer parte da própria identidade roraimense como as danças tradicionais das cirandas e quadrilhas juninas. Aliados a estas duas maiores influências junta-se número expressivo de pessoas de origem sulista que passou a compor a população do Estado, por meio de expressivo processo migratório do sul para o norte, como podemos observar no estudo de Carla Monteiro de Souza (2001), além de pessoas oriundas das diversas regiões do país que reforçam o aspecto multicultural de Roraima.

A identidade cultural roraimense é marcada por uma vasta diversidade, como apontamos. Contudo, são as culturas indígenas das diversas sociedades que formaram sua população que predominam desde sempre, considerando que existiam e ainda persistem o trânsito de diversos grupos indígenas comuns a região de fronteiras antes mesmo das disputas entre luso-brasileiros, holandeses, espanhóis e ingleses pelas Guianas e Amazônia Setentrional, no século XVII, definirem paulatinamente os limites de cada país deste espaço amazônico.

Analisando a diversidade cultural do Estado, buscamos investigar a pouca valorização para com as culturas indígenas e o obstáculos que envolvem suas representações artísticas na tentativa de se compreender o espaço e o valor das artes indígenas e sua afirmação de condição em iniciativas de divulgação. Após breve explanação sobre os aspectos culturais que envolvem o cenário roraimense, faremos uma exposição do patrimônio histórico e cultural do Estado, para posteriormente, analisarmos os preconceitos existentes, para assim discutirmos a importância das práticas de inclusão que vem sendo desenvolvidas pela universidade.

\section{Conhecendo o patrimônio histórico e cultural de Roraima}

O patrimônio histórico e cultural de uma cidade caracteriza a identidade, a cultura e o passado desta. Sendo assim, por meio da preservação do patrimônio mantemos sempre vivas e restauradas as raízes culturais de uma região. Além disso, o patrimônio de uma cidade faz parte de um processo de reconhecimento, como destacou Mário Chagas:

[...] o patrimônio cultural se constitui a partir da atribuição de valores, funções e significados aos elementos que o compõem. O reconhecimento de que o patrimônio cultural não é um dado, mas uma construção que resulta de um processo de atribuição de significados e sentidos, permite avançar em direção à sua dimensão política, econômica e social; permite compreendê-lo como espaço de disputa e luta, como campo discursivo sujeito aos mais diferentes usos e submetido aos mais diferentes interesses (CHAGAS, 2002, p. 137-138). 
Em se tratando dos elementos representativos que evocam as tradições e a cultura de Roraima, destacamos inicialmente o "Monumento aos Pioneiros", localizado na orla do Rio Branco, que foi criado pelo artista plástico Luíz Canará, em 1995, como parte de um plano discursivo sobre a constituição da sociedade roraimense, com a chegada dos pioneiros ao território e a assimilação pacífica dos índios. A obra, dá amplo destaque as primeiras famílias que colonizaram o Estado, e que mais tarde viriam a formar a classe política, minimizando a importância e singularidade das diversas etnias que aqui habitavam antes da presença do colonizador (cf. SANTOS, 2003).

O sítio arqueológico Pedra Pintada, localizado no sul do município de Pacaraima, na Reserva Indígena de São Marcos, também é outro importante patrimônio do Estado. Ela é parte de uma formação rochosa com aproximadamente 35 metros de altura, onde existe uma grande variedade de pinturas rupestres que datam em torno de 4.000 a 3.000 anos aproximadamente. $\mathrm{O}$ bem foi inscrito no Livro do Tombo Estadual em 1984 por abrigar vestígios que remontam a uma cultura ancestral. Por situar-se no interior de área indígena, o acesso ao sítio tem a observância da Fundação Nacional do Índio (FUNAI) que monitora e concede autorização para visitas (REIS; SCHOBBENHAUS; COSTA, 2008, p.10).

O Monte Roraima, monumento e paisagem natural de grande poder simbólico e marco da tríplice fronteira (Brasil, Venezuela e Guiana) é o elemento máximo de identificação do ser roraimense, pois da nome ao Estado e aparece em muitos dos símbolos do poder público local. Ele fica situado na área indígena Raposa Serra do Sol e é muito importante "para a identificação dos macuxi e dos outros povos que vivem ali: é o local sagrado deles, o local onde, segundo suas tradições, a humanidade surgiu" (ARRUDA, 2008, p.1).

Outro monumento que representa a cultura do Estado é o Monumento do Garimpeiro, criado em fins da década de 60 (cf. MARTINS, 2011) pelos artistas Walter Bastos de Melo e Francisco da Luz Moraes (conhecido como Japurá) representa a figura marcante do garimpeiro, que do mesmo modo que a figura do pioneiro, representa a contribuição do migrante na formação da sociedade roraimense (FETEC, 2011, p. 32). Sobre a sua estrutura:

Trata-se de uma estátua oca para permitir a vazão da água, que possui falsa aparência de concreto e em termos de suas dimensões, pode ser considerado um dos maiores monumentos da cidade de Boa Vista. Com uma rampa de 14 metros de comprimento, para permitir o acesso à sua parte frontal, está instalado sobre um espelho d'água retangular com 7,5 metros de largura por 15,70 metros de comprimento. O ponto mais alto da estátua atinge mais de sete metros de altura em relação ao chão da praça. Quando ligada, uma bomba dá vida ao Monumento, permitindo que a água escorra da bateia para o espelho sob a estátua simule a mineração em sistema de faisqueira, muito comum no início da exploração mineral em Roraima (MARTINS, 2011, p. 3). 
O Estado também conta com um imenso patrimônio imaterial. Entre eles destacamos: o modo com que a comunidade indígena Macuxi faz a panela de barro; o modo de fazer Paçoca com Banana (comida de origem indígena feita a base de farinha de mandioca e carne seca); a pesca da comunidade indígena Wapixana com o uso de uma planta chamada cunani e a produção de artefatos destas; o modo de fazer a Damorida (prato preparado com caldo de carne de boi, de caça ou de peixe com molho de pimenta e verduras); o Arraial Junino; o preparo do Caxiri (bebida, feita à base de mandioca, milenar dos povos Macuxi); a festa indígena Ajurí (festejo da plantação e da colheita); celebrações da Semana Santa. Contudo, apesar de toda sua representatividade, as tradições indígenas ainda são pouco valorizadas no Estado.

O patrimônio do Estado nas últimas décadas vem sendo alvo de estratégias de uma política cultural questionável, como no caso o "Projeto Raízes", idealizado na gestão da prefeita Teresa Jucá4 (1993-1996), cujo objetivo era "restaurar" prédios e praças históricas da capital Boa Vista. No entanto, a execução desse projeto ocorreu como reforma desses prédios, reformas essas que modificaram toda a estrutura original dos mesmos, afetando todas as características históricas destes bens patrimoniais. Uma das áreas mais afetadas da cidade com a execução do projeto foi a Orla Taumanan, local que no período de ocupação da cidade funcionava como porto, no qual desembarcaram os primeiros colonizadores de Boa Vista.

Descaso semelhante ocorre com a cultura indígena que vem sendo silenciada como elemento de destaque na formação identitária, enquanto isso alguns grupos sociais com maior poder econômico e político no Estado vêm privilegiando determinados bens de ordem material (casas e monumentos). Sobre essa seleção Canclini ressalta que

\footnotetext{
O patrimônio cultural serve, assim, como recurso para produzir as diferenças entre os grupos sociais e a hegemonia dos que gozam de um acesso preferencial à produção e distribuição dos bens. Os setores dominantes não só definem quais bens são superiores e merecem ser conservados, mas também dispõem dos meios econômicos e intelectuais, tempo de trabalho e de ócio, para imprimir a esses bens maior qualidade e refinamento (CANCLINI, 1994, p. 97).
}

Mediante uma clara e articulada estratégia de apoderamento do discurso dos indígenas e da eleição do não-índio como principal referência na constituição do Estado, as esferas do poder municipal e estadual tem empreendido esforços para manter uma história de versão única que privilegia um segmento em relação ao outro com clara ênfase a figura do migrante, garimpeiro, fazendeiro, enquanto o indígena ou está ausente ou é coadjuvante nessa construção. 
Após esta breve apresentação de alguns patrimônios históricos e culturais de Roraima - que ao mesmo tempo é tão diverso e com características predominantemente indígenas que são secundarizadas na formação identitária - passamos a seguir destacando as dificuldades dos artistas indígenas do Estado em divulgarem suas produções.

\section{Artes indígenas: as dificuldades no âmbito da divulgação}

O Estado de Roraima é um dos que possui maior diversidade cultural e linguística do Brasil com grupos ainda pouco contactados. Dentre os mais conhecidos destacam-se os Macuxi, Ingarikó, Wapixana, Iecuana, Taurepang, Wai-wai, Waimiri-atroari e Yanomani.

Entretanto, o conhecimento de suas práticas e representações artísticas e culturais ainda não é muito conhecida por uma parcela significativa da população. O Estado até pouco tempo não contava com uma galeria que pudesse dar visibilidade às artes plásticas de grupos indígenas. Recentemente foi inaugurado no município de Boa Vista a Galeria Jaider Esbell, um dos poucos espaços que dá visibilidade à arte de Roraima, em especial as obras de artistas indígenas.

Além desse local, existe um espaço de divulgação e comercialização de artefatos, o chamado "Centro de Artesanato", localizado na região da Orla Taumanan. Um ambiente é pouco frequentado pela população local, pela falta de divulgação das produções artísticas desse local. E espaços genéricos como o Centro Multicultural da Orla (gerido pela Prefeitura de Boa Vista), o Espaço União Operária (administrado pela Universidade Federal de Roraima) e a Galeria Franco Melchiori (SESC/RR).

Existem diversos artistas indígenas na região, mas apenas alguns conseguem dar visibilidade às suas produções artísticas, pela falta de incentivos e valorização do próprio Estado. As produções artísticas, em especial as indígenas, se deparam com sérias dificuldades para a divulgação de seus trabalhos.

As dificuldades da divulgação dos seus trabalhos, devem-se, em grande medida, pela falta de interesse dos gestores públicos. Esse caso é explicito nos editais de incentivo a cultura no Estado, que não têm dado importância aos artistas indígenas como um prêmio por segmento ou um edital especificamente voltado para as culturas indígenas. Na divulgação e promoção destes editais não se observa uma preocupação por parte dos gestores em familiarizar esses artistas e as comunidades com a produção de projetos para a participação nesses certames. 
A produção artística indígena ainda sofre muito preconceito, tanto no âmbito local como no nacional, grande parte desses preconceitos é oriunda da própria visão dogmática da sociedade capitalista, que identifica os grupos indígenas como "menos civilizados". A sociedade contemporânea ainda tem dificuldades em entender as transformações ocorridas nos grupos indígenas, que "[...] se renovam nos processos modernizadores suscitados pela urbanização e industrialização da cultura" (CANCLINI, 1994, p. 99).

Sendo assim, parte dessas dificuldades na exposição de suas produções, se deve a população do Estado não conhecer, nem reconhecer o valor da diversidade cultural dos povos indígenas, seus diferentes costumes e tradições, como elementos de maior destaque na formação da identidade roraimense. Isso em parte pelos conflitos que ocorreram durante a fixação dos pioneiros e garimpeiros - que foram eliminados da narrativa e história local, mas que subsistem sob a forma de latente preconceito - e, em parte, por não reconhecer que as produções desses grupos se transformam ao longo dos séculos, relegando-os, na maior parte do tempo ao produto decorativo e ornamental de caráter utilitário, sem o mesmo status de uma obra de arte que possa ter uma política específica de fomento e divulgação.

\section{As artes indígenas: conceitos e preconceitos}

Desde o advento da antropologia no século XIX as artes indígenas vem se tornando objeto de investigação sobre uma base teórica em que o conceito de arte tem demonstrado certa dificuldade de enquadramento e reconhecimento para se afirmar enquanto categoria universal. O problema era antigo e tinha relação com as muitas formas de tratamento do valor e juízo estético em sociedades não-ocidentais. Para construção de um conhecimento sobre a natureza destas perspectivas artísticas diferenciadas se produziu uma série de abordagens como a estruturalista (Lévi-Strauss), a semiótica ou semântica (Clifford Geertz), a da agência social (Alfred Gell), e aquela mais anterior em que se busca uma distinção entre a linha que separa o figurativo e o ornamental (Franz Boas). Desde então se concebeu que o ponto de discussão acabava por ser a tratativa do conceito de arte como resultado da singularidade da cultura e herança ocidental e, devido a isto, haver uma suposta incompatibilidade do emprego deste termo para com as produções de outros contextos como o da pluralidade dos povos denominados primitivos, tribais, aborígenes ou, simplesmente, indígenas. Estas produções eram na maior parte classificadas por cultura material com a afirmação de que as manifestações plásticas não visavam uma finalidade estética, mas sim a 
reprodução de conteúdos culturais ligados à questões como cosmologia e ou marcas distintivas do sistema tribal. Chegou-se a pensar até em qual termo lhe seria mais justo, sendo que autores como Singer passaram a atribuir o conceito de etnoarte considerando assim que este seria o mais adequado, "pois faz referência tanto a uma tradição plástica específica como pressupõe a contextualização sócio-cultural da arte" (VAN VELTHEM, 2003, p.86), correspondendo a um processo estético que estaria mais próximo da real intenção destes povos. Outros autores divergiam abordando tais práticas como "arte étnica", "arte tribal", "arte índia" ou "arte primitiva".

O problema da categorização persistiu durante longo tempo até o advento das novas perspectivas lançadas a partir de uma etnografia mais contemporânea (agenciamento, perspectivismo indígena) que buscava compreender o papel que a arte desempenhava nessas sociedades em sentido mais amplo possibilitou seu entendimento como algo para além do valor de ornamento ou do gosto e juízo de valor. No Brasil os trabalhos de pesquisadores no Brasil como Lux Boelitz Vidal, Regina Polo Muller, Barcelos Neto, Da Matta e Viveiros de Castro, dentre muitos outros, nos permitiu entender que qualquer noção singular de arte e cultura indígena torna-se genérica a medida que não comporta o universo de particularidades com que os valores estéticos que são construídas pelas diversas etnias. A pesquisadora Maria Isabel Cardoso da Silva ao tratar de abordagem de Van Velthem sobre este tema estabelece mesmo que aquilo que poderia ser tratado por arte em uma sociedade indígena se encontra em um campo muito mais alargado que nas sociedades ocidentais e que este campo está sempre em desenvolvimento como "arcabouços criativos", em que a visão de mundo se imprime em toda produção artística

Os valores reconhecidos e compartilhados nessa qualidade de "estar-no-mundo" se revelam através da "decoração", uma intervenção social, constituída como uma atividade artística e simbólica partilhada por todos os membros da sociedade onde se percebe um entrelaçamento entre a estética e os outros domínios do pensamento (SILVA, 2008, p. 35).

O emprego mais correto seria, portanto, se falar em sentido plural "Artes Indígenas", pois não haveria uma arte comum e geral dos índios (VAN VELTHEM, 2003, p.48), mas um conjunto multidiverso de manifestações artísticas de diversas etnias com suas particularidades que podem ser singularizadas pelo etnônimo indígena de cada sociedade em questão, havendo uma arte ingaricó, arte wai-wai, arte macuxi, arte wapixana, só para fazer menção a algumas das sociedades indígenas do Estado de Roraima. 


\section{O espaço da arte e o espaço das artes indígenas}

Podemos recordar que durante longo tempo considerou-se as artes e as manifestações estéticas indígenas como desprovidas de uma abordagem particularizada, pois estas eram vistas como consequências de transformações que ocorriam no âmbito mais interno de uma socioeconomia indígena onde os estudos concentravam-se basicamente nas relações de parentesco e no sistema de crenças. As artes ocupavam um papel secundário, pois, estando relacionada a uma ideia extracultural - supõe-se que os índios não viam suas criações como arte -, era rejeitada por alguns estudiosos até mesmo sobre a aplicação deste seu conceito à denominada cultura material, com a afirmação de que as manifestações plásticas indígenas não visavam uma finalidade estética, mas sim a reprodução de conteúdos culturais ligados à cosmologia ou a distinções hierárquicas internas.

O olhar construído sobre a arte não-ocidental foi fortemente marcado pelo positivismo e pelo evolucionismo do Século XIX e muitas das disciplinas até então relegavam às produções indígenas um caráter exótico que desconstruía em muito o outro enquanto sujeito de um saber específico capaz de operar por um pensamento complexo e um fundamento estético particularizado.

Este pensamento eurocêntrico ou norte atlântico dificultou em muito o reconhecimento do potencial das artes indígenas e seu pleno desenvolvimento em outros circuitos. Quando as produções artísticas indígenas eram expostas em centro urbanos europeus havia sempre uma barreira de alteridade construída ainda pela herança dos "Gabinetes de Curiosidades" que desconstruíam e descontextualizavam o outro pelo valor de exotismo.

Por outro lado o sistema de arte ocidental não demonstrava interesse em qualquer forma de diálogo horizontal com as produções artísticas indígenas que não fosse por meio da apropriação de formas e elementos plásticos segundo sua própria ótica de hegemonia cultural. Assim, os artistas das vanguardas europeias do início do Séc. XX, muito se utilizaram da arte africana, sem, contudo, promovê-la para além do colecionismo e da captura pictórica ou escultórica de referências formais traduzidas em suas obras.

Os primeiros museus foram ainda sob essa ótica da curiosidade e do exotismo e, como instituição cultural, tratou bem por separar e compartimentar as produções artísticas das sociedades não-ocidentais pelo rótulo de arte primitiva. Sally Price (2000) é uma crítica assídua da "defesa da descontextualização" e aborda com profundidade este tema ao discutir o quão primitiva seria essa 
arte se não faltasse a sensibilidade para que ela fosse contemplada sem as "lentes de uma educação cultural ocidental" (2000, p. 134).

Essa visão distópica foi responsável por refutar a exótico tudo aquilo que julga não se enquadrar em seus domínios. O espaço da arte, portanto, é um espaço dominado não apenas pela ótica ocidental que, mesmo tendo por pretensão tratar a arte como algo universal, se estabelece como legisladora sobre seu devir, mas também pelos personagens que compõem o sistema de arte, como críticos, curadores, gestores, marchands, galeristas e também os próprios artistas. Assim, ainda é comum tratarem a arte dos diversos grupos étnicos, como coisa menor, artesanato, objeto decorativo ou portador de valor primitivo.

Essa carga histórica e depreciativa que o termo primitivo comporta, é importante considerar, traz em si ainda a ótica evolucionista segundo a qual haveria uma cultura em atraso, vivendo ainda os "primórdios" da humanidade, e outra culta, a quem se auto-outorga o direito de "mostrar" o caminho da condução segura à civilização. Mesmo que estes artistas hoje reconheçam na produção um valor artístico e a si mesmo como artistas ainda são considerados primitivos ou tribais pela mesma exclusão com que foram impostos a nível social e cultural. Tidos ainda hoje como os “outros", nos esquecemos que já são um pouco de "nós" também. Ao etnocídio cultural que o relegamos estes resistiram com suas hibridizações que lhes permitem inovar suas produções artísticas cada vez mais ${ }^{5}$.

O espaço da arte formado pela cultura ocidental foi construído, portanto, para o nãoreconhecimento de epistemologias divergentes, mas para ser uma indústria de uma cultura globalizante e hegemônica que a tudo assimila e converte em mercadoria conforme vão surgindo novos públicos em novas fatias de mercado.

Contudo, se a arte moderna gerou toda uma sorte de apropriação imagética de elementos da cultura artística africana e da polinésia, hoje novos espaços vem sendo delineados para absorção de artistas indígenas protagonistas de seu processo de reconhecimento. São espaços mais autônomos como galerias abertas e coletivas, feiras e festivais comunitários e eventos expositivos com abrangência cada vez maior ${ }^{6}$.

Há desse modo uma urgência pela mudança de cenário em que não tenhamos acesso apenas a arte produzida por índios, mas a arte indígena contemporânea em pé de igualdade com a arte produzida por artistas não-indígenas. Neste espaço de arte indígena que vem se configurado pela agência e autoempoderamento pode caber o discurso direto a respeito de todas suas narrativas e a 
toda uma carga visual que tenha por compromisso uma visão específica de mundo tenha ela ou não um valor étnico de fundo.

No Estado de Roraima, já se notam iniciativas para alterar a construção social da imagem do índio que foi formada segundo um discurso marcado pro conflito pela posse de terras no recente período de colonização e ocupação do vazio demográfico iniciados no período da ditadura militar. À memória das famílias pioneiras, tombada como patrimônio pela Emenda Constitucional n. 021 (06/05/2008), já começa a surgir todo um conjunto de iniciativas fomentadas pelas instituições públicas e privadas e por organizações comunitárias e coletivos de artistas indígenas para que a promoção da arte e cultura das muitas etnias presentes no estado sejam devidamente fomentadas e o preconceito e intolerância cultural seja combatido.

Importante considerar que este preconceito foi durante muito tempo motivado por disputas entre indígenas e terras com posseiros e arrozeiros que teve grande cobertura da mídia e interferência do governo federal culminando em 2005 na homologação da Terra Indígena Raposa Serra do Sol, por decreto presidencial. Passados alguns anos os estereótipos e clichês quanto às diversas etnias que vivem no Estado são ainda muito presentes, sendo mais acentuado nas cidades próximas às comunidades indígenas.

Embora o governo do estado e as prefeituras tenham canais de articulação para atender as especificidades dessas sociedades como a Secretaria do Estado do Índio e a Secretaria Municipal de Gestão Ambiental e Assuntos Indígenas, a principal forma de solução desta situação ainda passa pela educação e cultura onde as instituições de ensino tem um papel fundamental.

\section{Artes indígenas nas práticas de ensino e extensão da UFRR}

A Universidade Federal de Roraima é a principal instituição de ensino superior do extremo norte do país e foi instituída pelo Decreto $\mathrm{n}^{\circ}$ 98.127, de 08 de setembro de 1989 . No que se diz respeito à infraestrutura física, a UFRR iniciou suas atividades em apenas um campus universitário, em uma área doada pelo governo do então Território Federal de Roraima. Atualmente a universidade adotou modelo multi-campi, com centros e demais unidades acadêmicas distribuídos em Cauamé, Murupu e Paricarana.

A questão indígena sempre foi objeto de interesse da política universitária da instituição que ganhou maior dimensão ao criar o Núcleo Insikiran, em 2001, fruto de reivindicação das organizações indígenas por uma oferta de cursos mais ajustada as suas realidades. Esta unidade 
acadêmica foi ampliada para Instituto Insikiran de Formação Superior Indígena, através da Resolução n. 009/2009-Cuni-UFRR, onde funcionam os cursos de Licenciatura Intercultural, Gestão Territorial Indígena e Saúde Coletiva Indígena. Mas, para além desta ação de grande impacto na formação indígena no Estado de Roraima, a UFRR tomou também a relevante iniciativa de criar em 2009, o primeiro curso na área de artes do Estado, a Licenciatura em Artes Visuais, sobre o qual trataremos com maior detalhe.

O curso de Artes Visuais foi instalado no Centro de Comunicação e Letras e passou a funcionar após a primeira contratação de professores, em 2010. Já neste ano foram feitas as primeiras alterações no Projeto Político-Pedagógico do Curso de Artes Visuais no sentido de garantir que a dimensão étnica e identitária estivessem contempladas nas práticas de ensino, pesquisa e extensão.

Essa reforma no PPC tomou por base a abordagem transdisciplinar como forma contribuir para um novo tipo de Educação, a partir de quatro pilares, elaborados pela Comissão Internacional sobre Educação para o Século XXI, ligada à UNESCO e presidida por Jacques Delors, a saber: aprender a conhecer, aprender a fazer, aprender a viver em conjunto e aprender a ser (NICOLESCU, 1999).

Aprender a conhecer significa ter acesso aos saberes e ao espírito científico, estimulando o questionamento desse conhecimento, a pesquisa e a construção de pontes entre os diferentes saberes e suas significações na vida cotidiana.

Aprender a fazer significa a aquisição de uma profissão, o que passa, necessariamente, por uma especialização. No entanto, é preciso esclarecer que especialização não significa reducionismo a um modo único de pensar ou fazer.

Aprender a viver em conjunto significa, de modo geral, o respeito às normas da coletividade, mas significa, sobretudo, "reconhecer-se a si mesmo na face do outro". Tratase de um aprendizado permanente de tolerância e afetividade que inclui a atitude transcultural, transreligiosa, transpolítica e transnacional.

Aprender a ser significa "descobrir nossos condicionamentos, individual e social, especialmente, os relacionados às certezas" (NICOLESCU, 1999).

Estes princípios podem ser compreendidos como indicadores da organização transdisciplinar do conhecimento, de modo a tornar abrangente a estrutura dos curso de Artes Visuais, em consonância com as novas demandas sociais.

Neste sentido foram criadas as disciplinas "Arte e Representações Culturais na Amazônia"; “Arte, Memória e Patrimônio" e, "Arte, Educação e Diversidade Cultural”. Estas três disciplinas, em conjunto com as disciplinas laboratoriais onde são desenvolvidas práticas de ateliê, são as 
responsáveis por reunir a maior parte da contribuição indígena através da inclusão de saberes na prática de ensino e aprendizagem do curso de Artes Visuais da UFRR.

A disciplina "Arte e Representações Culturais na Amazônia", tem por foco a Amazônia Continental e suas relações com as sociedades indígenas, ribeirinhas e com a sociedade nacional, bem como os processos migratórios, hibridização cultural e etnografias contemporâneas da cultura e da arte.

A disciplina "Arte, Memória e Patrimônio" aborda a experiência estética e aprendizagem artística em museus e espaços culturais tendo por referência a contribuição indígena na formação cultural da sociedade roraimense. Para tanto, propõe uma investigação crítica sobre patrimônio histórico-artístico e as formas de mediação cultural nos museus da região norte.

Já a disciplina “Arte, Educação e Diversidade Cultural” atua na perspectiva da educação pós-moderna, efetuando análise sobre as representações visuais e as relações de poder na região, abarcando temas como identidade, alteridade, diversidade e multiculturalismo.

Nestas disciplinas os professores e alunos de ascendência indígena e não-indígena do curso de Artes Visuais realizam suas prática de ensino e aprendizagem entremeadas com incursões à campo, visita aos ateliês dos artistas locais, realização de estudos sobre arte regional e registro fotográfico e audiovisual sobre a presença cultural indígena na construção identitária roraimense. Neste caso, as ações são norteadas pelo Plano Nacional de Educação (PNE) e pela política cultural nacional que propõe a valorização dos mestres dos saberes e fazeres como reflexo do programa Tesouros Humanos Vivos da UNESCO.

Nas práticas de ensino os professores são estimulados a propor a articulação de saberes com a comunidade externa na construção de produtos artísticos (vídeos, fotografias, pinturas, desenhos e gravuras). Estas ações têm por eixo transversal a Diversidade Cultural e culminam sempre no início e término de cada semestre com os eventos acadêmicos do curso de Artes Visuais. Estes eventos são organizados pelos alunos e professores e visam estreitar e fortalecer as relações entre a universidade e a sociedade. Os principais eventos realizados pelo curso são: Semana de Recepção dos Alunos de Artes Visuais (Artecalourosa), Seminário Integrado de Arquitetura e Artes Visuais (INTEGRA) e Seminário Interdisciplinar de Artes Visuais.

A Semana Artecalourosa é realizada anualmente no segundo semestre letivo e reúne práticas de ensino e extensão planejadas e desenvolvidas para integração dos alunos calouros recepcionados pelos colegas na condição de monitores e voluntários. Entre as atividades são ofertadas oficinas, 
palestras e seminários com artistas, pesquisadores e atores culturais locais para dialogar sobre os temas artísticos mais relevantes para região norte. Dentre estes temas destacam-se a memória, identidade cultural, arte e etnicidade que é corrente nas produções artísticas apresentadas.

O Seminário Integrado de Arquitetura e Artes Visuais (INTEGRA) também ocorre anualmente e congrega alunos dos cursos de artes e arquitetura, além de estudantes das diversas IES do Estado de Roraima. As ações desenvolvidas no INTEGRA buscam construir uma ponte entre o conhecimento das duas áreas com ênfase na realidade amazônica e nos desafios e reflexos identitários e culturais nas práticas de ensino, pesquisa e extensão. Neste evento, que corresponde a semana acadêmica, os alunos juntamente com os professores atuam na produção cultural, mediação de debates, montagem de exposições e discussão de temas em palestras, mesas redondas e sessões de comunicação com a participação de artistas indígenas, arquitetos, mestres da cultura, pesquisadores institucionais, gestores públicos e arte-educadores.

O Seminário Interdisciplinar de Artes Visuais é um evento semestral que articula ensino e extensão com a diferença de que nele se ressalta, principalmente, o caráter avaliativo e a interdisciplinaridade na produção e divulgação do conhecimento, uma vez que os resultados produzidos nas disciplinas (apresentações, artigos científicos, relatos de experiência, trabalhos artísticos) são expostos e avaliados com a presença e contribuição da comunidade em espaço aberto para ampla visitação.

A interdisciplinaridade, como trabalhada no curso é uma prática de negociação entre pontos de vista, projetos e interesses diferentes. Ela pressupõe uma interação das disciplinas e uma interpretação que possa trilhar desde a simples comunicação de ideias até a integração dos conceitos, sendo, assim, parte da organização do conhecimento.

A interdisciplinaridade centrada na articulação dos saberes, pode se estabelecer, de acordo com Sônia Penin (1994), como:

Conhecimento sistematizado: aquelas formulações consideradas válidas pela epistemologia, com base no método científico, que formam um corpo de conceitos, organizados e teorias bem definidas e, ainda, aqueles organizados por diferentes disciplinas no campo das artes, das humanidades etc.

Saber cultural: formas de conhecimento, como os chamados cotidiano, leigo, tradicional ou empírico, em uma dada cultura que apresentam níveis variados de elaboração, provenientes da mídia, da política, de regionalismos e de outros lugares.

Os resultados destas práticas do curso tem sido avaliados em seminários abertos a comunidade para avaliação do PPC, como ocorrido em 2012, no qual os alunos, professores e 
público em geral reuniram-se para avaliar o percurso das ações, propor alterações e fazer sugestões de melhoria da matriz curricular e demais tópicos. Este modelo mostrou-se satisfatório por ter acarretado em melhorias significativas na flexibilização da grade de disciplinas para que os discentes possam melhor definir seu percurso formativo. Entretanto, a comunidade externa ainda tem se mostrado pouco envolvida por considerar este um processo circunscrito ao círculo acadêmico. Para proporcionar uma maior articulação e participação destes para com a universidade foi criado o projeto de extensão Arte no Campus, também vinculado ao curso, que proporciona a interação de alunos voluntários como instrutores de oficinas abertas ao público, com itinerância em bairros da cidade e exposição de trabalhos artísticos para divulgação da produção discente.

O impacto destas ações tem sido cada vez mais amplos, agregando trabalhos de cerca de $60 \%$ dos alunos e atingindo três bairros da cidade. Contudo, a falta de recursos tem limitado o maior aumento desta ações que dependem de editais internos para apoio financeiro por parte da PróReitoria de Assuntos Estudantis e Extensão. Para solucionar essa equação são feitas parcerias com instituições da Prefeitura e Governo do Estado para garantir os espaços expositivos e apoio de montagem dos trabalhos.

No âmbito da pesquisa o AMA[Z]OOM - Observatório Cultural da Amazônia e do Caribe (UFRR/CNPq) vinculado ao curso de Artes Visuais tem desenvolvido ações articuladas com as disciplinas do curso, principalmente no sentido de identificar as imagens e representações dos índios no discurso visual dos artistas roraimenses por meio da "Cartografia Cultural do Estado de Roraima", uma base de dados sobre as informações culturais que contou com dois subprojetos: "Mapeamento dos Painéis e Murais artísticos da cidade de Boa Vista" e o "Mapeamento do Artesanato e Arte Popular do Estado de Roraima”, realizados no período 2011-2012. Alguns destes estudos foram ampliados no Programa Institucional de Bolsas de Iniciação Científica (CNPq/UFRR), em 2012, quando foram catalogados 12 painéis executados nos anos 80, a maioria em madeira com temática cultural indígena, alguns em estado de abandono e deterioração. Mas não foi dada sequência à pesquisa pela sobrecarga de funções dos docentes e pela dificuldade de acesso às informações e exemplares nos espaços e bases de dados nas instituições públicas no Estado.

Outro papel importante na articulação de saberes tradicionais indígenas e na promoção cultural e artística das diversas etnias do Estado tem sido desempenhado pela Pró-Reitoria de Assuntos Estudantis e Extensão (PRAE), no fomento a alguns projetos e programas voltados as sociedades indígenas como o Programa de Valorização das Línguas e Culturas Macuxi e 
Wapichana, a Incubadora Tecnológica de Cooperativas Populares e Economia Solidária e o Polo Arte na Escola, que tem desempenhado atividades em comunidades indígenas na dimensão artística e cultural, na articulação comunitária e fomento a projetos e nos aspectos de ensino e aprendizagem em diálogo com a educação intercultural.

A Universidade Federal de Roraima tem enfrentado o desafio de ser uma instituição com enfoque nas relações fronteiriças e na diversidade étnica e cultural. Ainda são muitos os problemas a serem superados, muito em função da sua recente consolidação na região, mas os resultados começam a aparecer e os impactos se mostram positivos e cada vez melhores. A falta de uma estrutura física melhor adaptada e de carência de equipamentos vem sendo superada e hoje já dispõe de um espaço expositivo próprio como a União Operária no qual frequentemente ocorrem ações de promoção da cultura indígena. Novos desafios vão surgir, contudo é importante que o enfoque permaneça e tanto o curso de Artes Visuais e quanto a Pró-Reitoria de Extensão tem demonstrado um desejo de constante aproximação com os artistas indígenas para construção de um projeto comum de sociedade.

\section{Considerações Finais}

Considerando as discussões apontadas nesse texto compreendemos que o patrimônio artístico e cultural do Estado vem sendo terreno de interesses políticos desde longa data, sendo instrumentalizado ainda por uma história de versão única que relega o elemento indígena a plano secundário de coadjuvante sem o efetivo reconhecimento da contribuição da diversidade étnica à formação da identidade cultural roraimense. Esse ofuscamento é causado por preconceitos contra a população indígena que foram recentemente acirrados pela criação da TI Raposa Serra do Sol e retirada de fazendeiros instalados nestas áreas indígenas. Essa situação acaba por não favorecer que a classe política crie políticas de apoio e fomento às artes indígenas, uma vez que são justamente os empresários e fazendeiros, alguns deles descendentes das famílias dos pioneiros, que compõe tal classe.

Contudo, os artistas tem se organizado e promovido suas ações de divulgação e promoção cultural por iniciativa própria e ganhado pouco a pouco visibilidade no contexto local. Para tanto tem contribuído as práticas de ensino e extensão desenvolvidas pela UFRR, por meio dos cursos de graduação, como o de Artes Visuais, e de projetos e programas extensionistas e comunitários apoiados pela PRAE. 


\section{Referências}

CANCLINI, Nestor García. O patrimônio cultural e a construção imaginária do nacional. Revista do Patrimônio Histórico e Artístico Nacional, no 23. Rio de Janeiro, 1994.

CHAGAS, Mário. Cultura, Patrimônio e Memória. In: INTEGRAR, $1^{\circ}$ Congresso Internacional de arquivos, bibliotecas, centros de documentação e museus: textos. São Paulo: Imprensa Oficial do Estado, 2002.

FUNDAÇÃO DE EDUCAÇÃO, TURISMO, ESPORTE E CULTURA DE BOA VISTA - FETEC. Inventário do Patrimônio Cultural de Boa Vista. Boa Vista: Gráfica Lóris, 2011.

MARTINS, Elisangela. Memórias de disputas e disputas pela memória na praça central de Boa Vista, RR. In: Anais do XXVI Simpósio Nacional de História - ANPUH. São Paulo, julho de 2011.

NICOLESCU, B. O Manifesto da transdisciplinaridade. Tradução de Lúcia P. de Souza. São Paulo: Triom, 1999.

PENIN. Sônia T. de Sousa. A aula como espaço de conhecimento, lugar de cultura. Campinas, Papirus, 1994.

PRICE, Sally. Arte primitiva em centros civilizados. Tradução Inês Alfano. Rio de Janeiro: Editora UFRJ, 2000.

RIBEIRO, Darcy et al. Suma etnológica brasileira.Volume 2. Petrópolis: Vozes, 1987.

REIS, N.J.; SCHOBbenhaus, C.; COSTA, F. 2008. Pedra Pintada, RR - Ícone do Lago Parime. In: Winge, M.; Schobbenhaus, C.; Souza,C. R. G.; Fernandes,A. C. S.; Berbert-Born, M.; Queiroz, E. T.; (Edit.) Sítios Geológicos e Paleontológicos do Brasil. Disponível em: <<atualmente http://www.sigep.cprm.gov.br/sitio012/sitio012.pdf >>. Acesso em: 15 de abril de 2013.

SANTOS, Raimundo Nonato Gomes dos. Roraima: a construção de identidades políticas indígenas e não indígenas no final do século XX. Dissertação de mestrado, UFRJ/IFCS/PPGHIS, 2003. 180p.

SILVA, Maria Isabel Cardoso. "Cosmologia, Perspectivismo e Agência Social na Arte Ameríndia: Estudo de três casos etnográficos". 2008. 171fl Dissertação (Mestrado em Antropologia) - Curso de Pós-Graduação em Antropologia, Faculdade de Filosofia e Ciências Humanas, Universidade Federal de Minas Gerais. Belo Horizonte - MG, 2008.

SOUZA, Carla Monteiro de. Gaúchos em Roraima. Porto Alegre: EDIPUCRS, 2001.

VAN VELTheM, Lúcia H. O Belo é a Fera. A Estética da Produção e Predação entre os Wayana. Lisboa: Assírio e Alvim, 2003. 


\section{Notas:}

\footnotetext{
${ }^{1}$ Este artigo decorre de pesquisas realizadas no âmbito do AMA[Z]OOM - Observatório Cultural da Amazônia e do Caribe (CNPq/UFRR) e do projeto de pesquisa "Os lugares de memória versus interesse político: uma análise sobre o descaso com o patrimônio cultural em Roraima".

${ }^{2}$ Mais informações sobre este assunto podem ser encontradas no site institucional do Governo do Estado de Roraima (http://www.rr.gov.br./)

${ }^{3}$ Cf. SILVEIRA, Isolda Maciel; GATTI, Marcelo. Notas sobre a ocupação de Roraima, migração e colonização. Boletim do Museu Paraense Emílio Goeldi, Belém, v. 4, n. 1, p. 43-66, jul.1988.

${ }^{4}$ Atualmente Teresa Surita (nome alterado após divórcio do político Romero Jucá) exerce a função de prefeita de Boa Vista (gestão 2013-2017).

${ }^{5}$ Referimo-nos ao manto tupinambá levado pela corte do Príncipe de Nassau para Copenhange no século XVII para fazer parte de gabinetes de curiosidades europeus. Tal manto retornou ao Brasil para as comemorações dos 500 anos de seu "achamento" e pode ser ambientado junto com outras peças históricas, mas, ainda assim, figurou como documento antropológico quando na verdade é um dos maiores exemplares da arte indígena.

${ }^{6}$ Um exemplo de evento foi o "Mira! Artes Visuais Contemporâneas Indígenas", de abrangência nacional, na qual que participado o artista indígena roraimense Jaider Esbell.
} 